\title{
МОРФОСТРУКТУРА ЮГО-ЗАПАДНОГО ЗАБАЙКАЛЬЯ
}

\author{
О. В. Жаворонкин ${ }^{1}$ А. И. Трегуб ${ }^{1,2}$ \\ ${ }^{1}$ Воронежский государственный университет \\ ${ }^{2}$ Старооскольский филиал МГРИ
}

Поступила в редакцию 29 августа 2019 г.

\begin{abstract}
Аннотация: в работе приведень результатьл морфоструктурного анализа территории югозападного Забайкалья, основанные на построении стохастических моделей рельефа. Проведено морфоструктурное районирование территории, выявлено блоковое строение рельефа, а также общий линейный характер с преобладающей северо-восточной ориентировкой осей. Для наиболее крупных морфоструктурных элементов определены морфометрические параметры, выполнена оценка активности вертикальных тектонических движений на современном и неотектоническом этапах развития, что позволило сделать вывод о распространении условий слабых современных отрииательных вертикальных тектонических движений. Методика морфометрического анализа, базирующаяся на стохастических моделях рельефа, может быть включена в комплекс методов изучения неотектонических и современных тектонических движений при геологическом изучении территории Забайкалья.
\end{abstract}

Ключевые слова геоморфология, морфоструктурный анализ, стохастические модели рельефа.

\section{MORPHOSTRUCTURE OF THE SOUTH-WESTERN TRANSBAIKALIA}

\author{
O. V. Zhavoronkin ${ }^{1}$, A. I. Tregub ${ }^{1,2}$ \\ ${ }^{1}$ Voronezh State University, \\ ${ }^{2}$ Moscow Geological Exploration Institute, Starooskolsky branch
}

Received 29 August 2019

\begin{abstract}
: the paper presents the results of a morphostructural analysis of the territory of southwestern Transbaikalia, based on the construction of stochastic relief models. Morphostructural zoning of the territory was carried out, a block relief structure was revealed, as well as a general linear character with a predominant northeast orientation of the axes. For the largest morphostructural elements, their morphometric parameters were determined, the activity of vertical tectonic movements at the modern and neotectonic stages of development was estimated, which made it possible to conclude that the conditions of weak modern negative vertical tectonic movements are spread. The methodology of morphometric analysis based on stochastic relief models can be included in a set of methods for studying neotectonic and modern tectonic movements in a geological study of the territory of Transbaikalia.
\end{abstract}

Key words: geomorphology, morphostructure analysis, relief stochastic models.

Район исследований расположен в центральной части республики Бурятия в бассейне рек Селенга, Хилок и Чикой, к югу от оз. Байкал до государственной границы с Монгольской Народной Республикой. Территория относится к Центрально-Азиатскому складчатому поясу, обрамляющему с юга Сибирскую платформу, и находится на сочленении СаяноПрибайкальской и Тувино-Забайкальской складчатых систем (рис. 1).
В тектоническом отношении она представляет эпиплатформенный ороген на байкальском основании, активизированный в кайнозое в результате внутриплитных тектономагматических процессов и рифтогенеза $[1,2,3]$. Земная кора в пределах района и сопредельных территорий является типично континентальной, со средней мощностью от 40 до 44 км. Локальное уменьшение толщины коры до 32-34 км отмечается только под оз. Байкал. Мощность

(C) Zhavoronkin O. V., Tregub A. I., 2019 


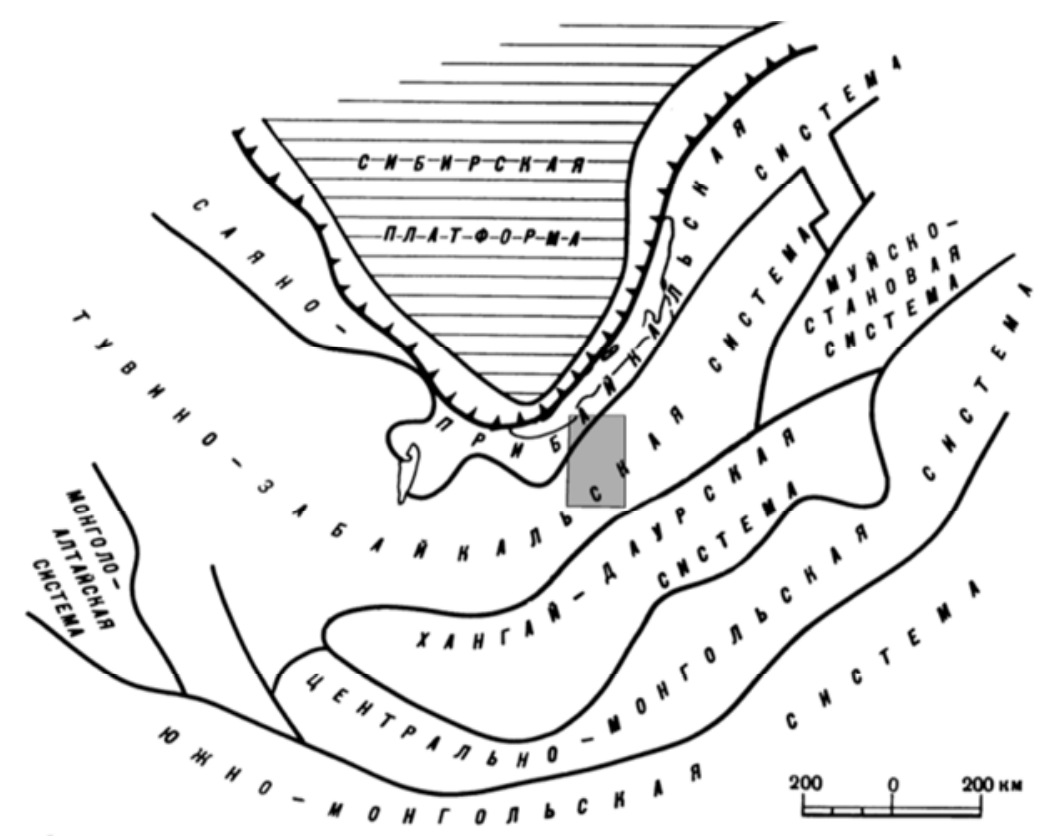

Puc. 1. Положение изученной территории (выделена затененным прямоугольником) в пределах области байкальской складчатости.

литосферы составляет около 100 км, в сторону Байкальской впадины она уменьшается до 50 км. Астеносферный выступ приурочен к Байкальской рифтовой зоне, активно развивающейся в кайнозое [2].

В методическом отношении важно установление для региона характера связи рельефа, его морфоструктуры, с геологическим строением, неотектоническими и современными тектоническими движениями, степенью унаследованности этих движений от более древней структуры.

При изучении особенностей морфоструктурного плана использованы результаты анализа стохастических моделей рельефа. Эти модели представлены центральными моментами распределений высот земной поверхности в скользящих окнах осреднения [4]. Среди них: математическое ожидание, несмещенная дисперсия и стандартное отклонение, эксцесс распределения и коэффициент его асимметрии, а также экстремумы функции распределения [5]. В настоящей работе приведены карты экстремумов функции распределения высот (вершинной и базисной поверхностей), а также стандартных отклонений (энергии рельефа) и коэффициентов асимметрии. Первые две карты представляют морфологическую характеристику земной поверхности и ее соотношение с глубинными неоднородностями [6, 7]. Карта стандартов (энергии рельефа) отражает запасы потенциальной энергии, выраженные в перепадах высот между вершинной и базисной поверхностью. Эти запасы образуются за счет кинетической энергии неравномерных вертикальных тектонических движений и расходуются на проявление экзогенных геодинамических процессов. Они, таким образом, позволяют дать оценку суммарным вертикальным движениям неотектонического этапа в развитии территории. Карта коэффици- ентов асимметрии распределения высот отражает соотношение высот больших, чем средние с высотами меньшими, чем средние. Такие соотношения отражают положение рельефа в геоморфологическом цикле и дают возможность сделать выводы о распределении по площади современных вертикальных движений [5]. На основе анализа всех этих карт составлена морфоструктурная схема территории (рис. 2). Основной особенностью морфоструктуры является ее блоковый характер, где положительные элементы выражены хребтами протяженностью в сотни километров, опущенные - мезозойскими и кайнозойскими депрессиями.

Для основных морфологических элементов характерен общий линейный характер с преобладающей северо-восточной ориентировкой осей. По особенностям этой ориентировки территорию можно разделить на две части. Первая - охватывает левобережье Селенги и представлена Хамар-Дабанским и Моностойским поднятыми блоками, которые ограничены УстьСеленгинской и Гусино-Удинской депрессиями (рис. 1). Они обладают устойчивым простиранием осей CB $40^{\circ}-50^{\circ}$. Вторая, правобережная, часть бассейна Селенги, включающая все остальные блоковые морфоструктуры территории, отличается общим разворотом осей до азимута СB $60^{\circ}-70^{\circ}$.

На карте вершинной поверхности отчетливо проявляются морфологические особенности морфоструктуры, ее детали (рис. 3). На левобережье Селенги Хамар-Дабанский поднятый блок (I) сопоставляется с одноименным хребтом с максимальными высотами, превышающими 1500 м, и отделяет серию мезозойских впадин (самая крупная из которых - ГусиноУдинская - XI) от южного обрамления Байкальского рифта. В пределах этой впадины отметки вершинной 


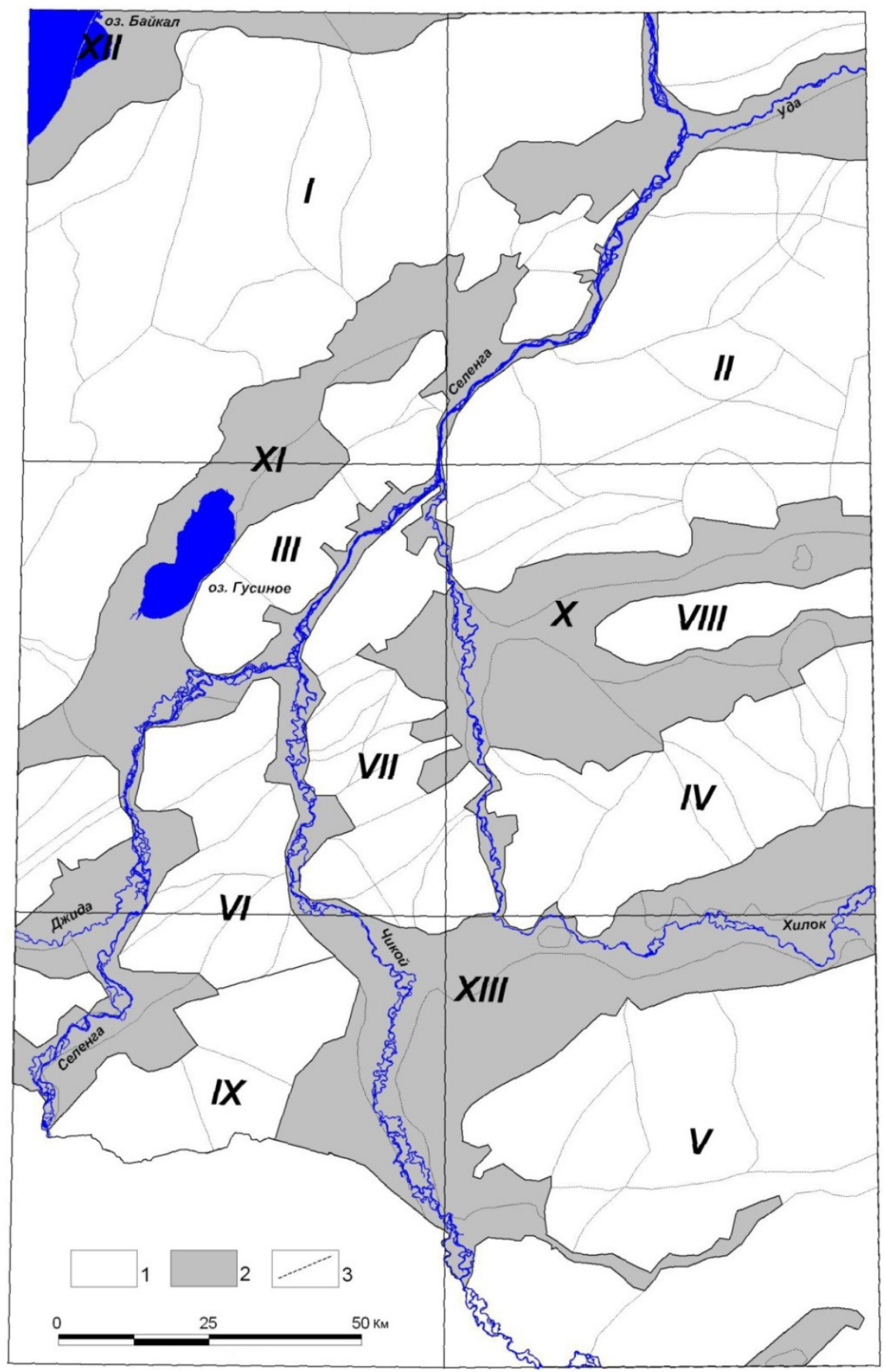

Puc. 2. Морфоструктурная схема юго-западного Забайкалья. Условные обозначения. 1 - положительные морфоструктуры первого порядка: $I$ - Хамар-Дабанский блок; $I I$ - Цаган-Дабанский блок; $I I I-$ Моностойский блок; $I V$ - Заганский блок; $V$ - Малханский блок; VI - Харгантуйский блок; VII - Черногривенский блок; VIII - Тугнуйский блок; $I X$ - Черносопкинский блок; 2 - отрицательные морфоструктуры I порядка: $X$ - Тугнуйская впадина; XI - Гусино-Удинская депрессия; XII - Усть-Селенгинския и Селенгино-Итанцинская впадины; XIII - Хилок-Чикойская впадина; 3 - границы морфоструктур II порядка.

поверхности резко понижаются до 550 м. Внутреннее строение впадины осложнено серией понижений, вытянутых в северо-восточном направлении. Моностойский поднятый блок (III) представляет собой узкую структуру с максимальными высотами до 1000 м. Для обоих поднятых блоков характерно мозаичное внутреннее строение и отчетливо выраженные ограничения, проявленные в градиентах высоты вершинной поверхности.
Юго-восточная часть территории (правобережье Селенги) характеризуется меньшей линейностью блоков, менее четкими их ограничениями. Поднятый блок Цаган-Дабанский (II), в пределах которого высота вершинной поверхности увеличиваются до 1400 м, с юго-востока ограничивается Тугнуйской депрессией (X), которая в осевой части разделяется Тугнуйским горстом (VIII) с максимальными высотами вершинной поверхности до 950 м. 


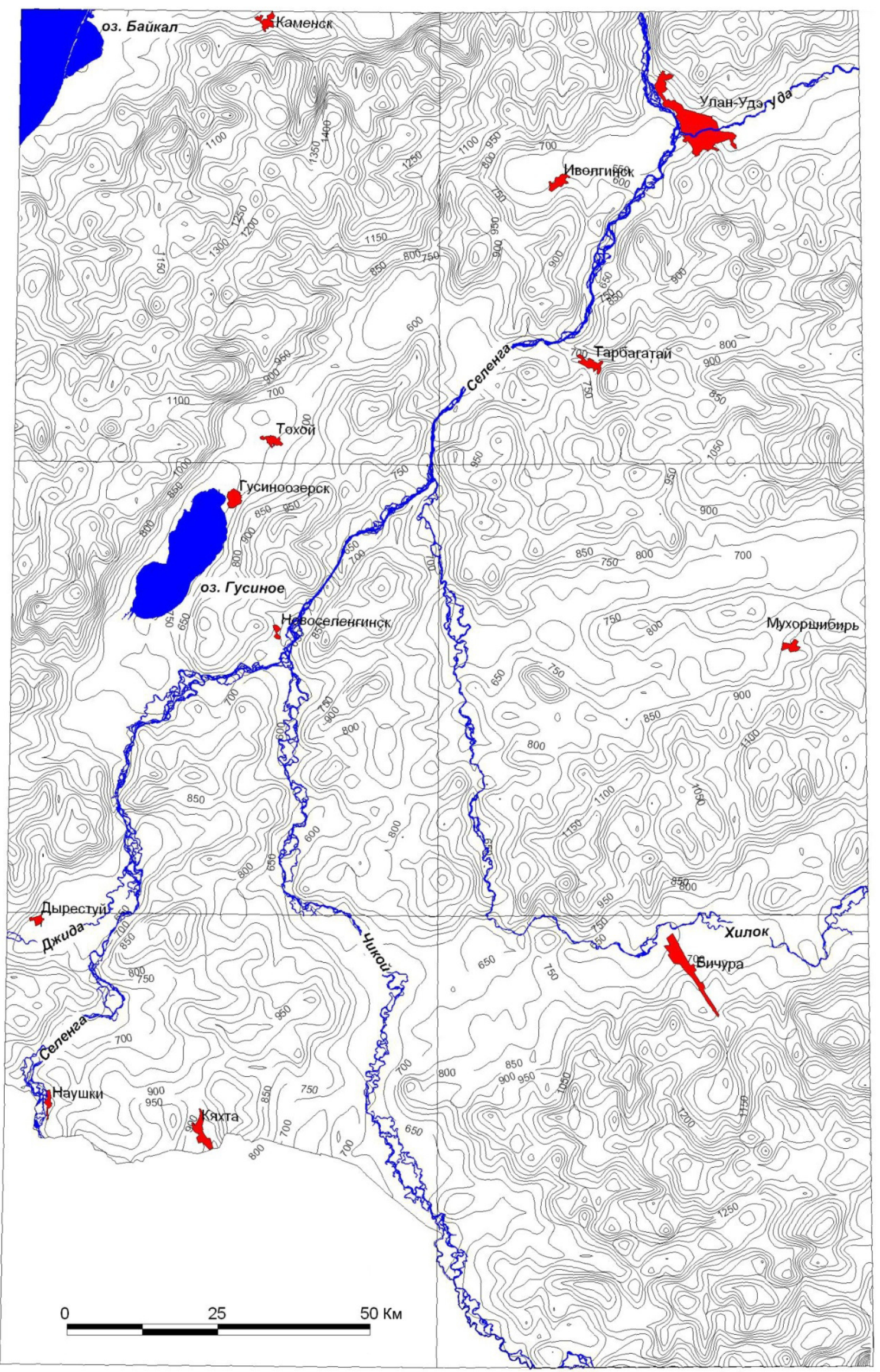

Puc. 3. Карта вершинной поверхности рельефа юго-западного Забайкалья. 
Южный борт Тугнуйской депрессии ограничен Заганским блоком (IV). Границы этого блока очень четкие, а вершинная поверхность достигает здесь отметок 1300 м. Юго-восточную часть территории занимает Малханский блок $(\mathrm{V})$, имеющий сложное строение. Значение вершинной поверхности здесь достигает на отдельных участках 1700 м.

Юго-западная часть района (правобережье Селенги) отличается менее четкими границами крупных морфоструктур с перепадами высот существенно меньшими, чем в северной части территории. Из поднятых морфоструктур выделяются Харгантуйский (VI), Черногривенский (VII) блоки. Максимальные отметки высот вершинной поверхности здесь находятся в пределах 1000 м. Общая ориентировка осей этих структур северо-восточная со значительными отклонениями.

Базисная поверхность приближается по своей форме к уровенной поверхности, а следовательно, может отображать распределение плотностей в литосфере. Она, таким образом, позволяет характеризовать глубинную природу морфоструктур [5]. В пределах правобережной части бассейна Селенги базисная поверхность в наиболее общих чертах повторяет морфологические очертания вершинной поверхности, что дает возможность судить о генетической общности контролирующих их глубинных структур (рис. 4). В области Хамар-Дабанского блока максимальные значения высоты базисной поверхности составляют 1200 м. Также отчетливо, как и на вершинной поверхности, проявлены его границы. Инфраструктура Гусино-Удинской впадины в базисной поверхности характеризуются более резкими очертаниями образующих ее локальных отрицательных морфоструктур, разделенных небольшими локальными поднятиями. Сходными особенностями отличается и примыкающая к Байкалу Усть-Селенгинская депрессия. У Моностойского блока в базисной поверхности по сравнению с вершинной поверхностью более отчетливо выражена его юго-восточная граница.

Юго-восточная часть территории характеризуется более однородным распределением высот базисной поверхности (500-800 м) и лишь в контурах Малханского блока она достигает 1000 м. Области повышенных значений имеют преимущественно вытянутую линейную форму северо-восточного, субмеридионального и субширотного простираний.

На картах коэффициентов асимметрии и энергии рельефа отчетливо разделяются северо-западная и юго-восточная части территории (рис. 5). Значения коэффициентов асимметрии распределения высот для Хамар-Дабанского блока находятся в основном в области отрицательных значений, что свидетельствует об активных современных поднятиях территории (рис. 5А). Усть-Селенгинская впадина, ограничивающая Хамар-Дабанский блок на северо-западе, характеризуется положительными значениями асимметрии, фиксирующими активное современное тектоническое погружение.

Вся остальная территория по коэффициенту асим- метрии располагается преимущественно в области положительных значений, что позволяет утверждать ее развитие в условиях слабых современных отрицательных вертикальных тектонических движений.

По коэффициенту асимметрии распределения высот выделяются узкие протяженные зоны чередования локальных положительных и отрицательных значений, свидетельствующие о резко дифференцированном характере вертикальных движений, присущих зонам активных разломов.

Северо-западная и юго-восточная части территории отличаются и по величине энергии рельефа (рис. 5B). Ее повышенные значения отмечаются для западной части Хамар-Дабанского блока, а в пределах правобережья Селенги - для южной части Малханского блока. Из чего следует, что эти территории были наиболее активны на неотектоническом этапе.

Полученные результаты морфоструктурного анализа сопоставлены с имеющимися геологическими данными [8-10]. Хамар-Дабанский блок на протяжении мезозоя и кайнозоя занимал гипсометрически более высокое положение, хотя и имел меньшие размеры. Это подтверждается фациальным анализом структурно-вещественных комплексов палеогенового возраста в юго-восточных приграничных частях структуры. В течение всего неотектонического этапа, блок испытывает интенсивное поднятие, что подтверждает отсутствие неоген-четвертичных образований в его пределах. На неотектоническом этапе размеры структуры постепенно увеличиваются, в восходящие вертикальные движения вовлекаются приграничные территории [8].

Усть-Селенгинская впадина испытывала местное погружение на фоне общего поднятия территории. Сушествовавшие в палеогене и в начале неогена обширные бассейны седиментации в плиоцене и в квартере замещаются озерно-болотными и озерноречными условиями аккумуляции [9]. Существовавшие в раннем неоплейстоцене области аккумуляции вещества, постепенно сужаются и перемещаются к осевым частям депрессии.

Анализ вещественного состава палеогеновых и неогеновых структурно-вещественных комплексов позволяет сделать вывод о том, что после окончания этапа активного формирования Гусино-Удинской впадины, в конце мезозоя наступает этап относительного тектонического равновесия этой территории. Депрессия представляет в это время единый консолидированный массив. Незначительное погружение дна впадины, компенсируется региональным поднятием территории в целом. Судя по составу четвертичных образований, в течение всего четвертичного этапа впадина погружалась относительно соседних - Хамар-Дабанского и Моностойского блоков. По всей длине Гусино-Удинской впадины ее борта осложнены неотектоническими разломами, ориентированными вкрест простирания впадины. В современном рельефе эти разрывные нарушения выражены небольшими долинами и тектоническими уступами [10]. 


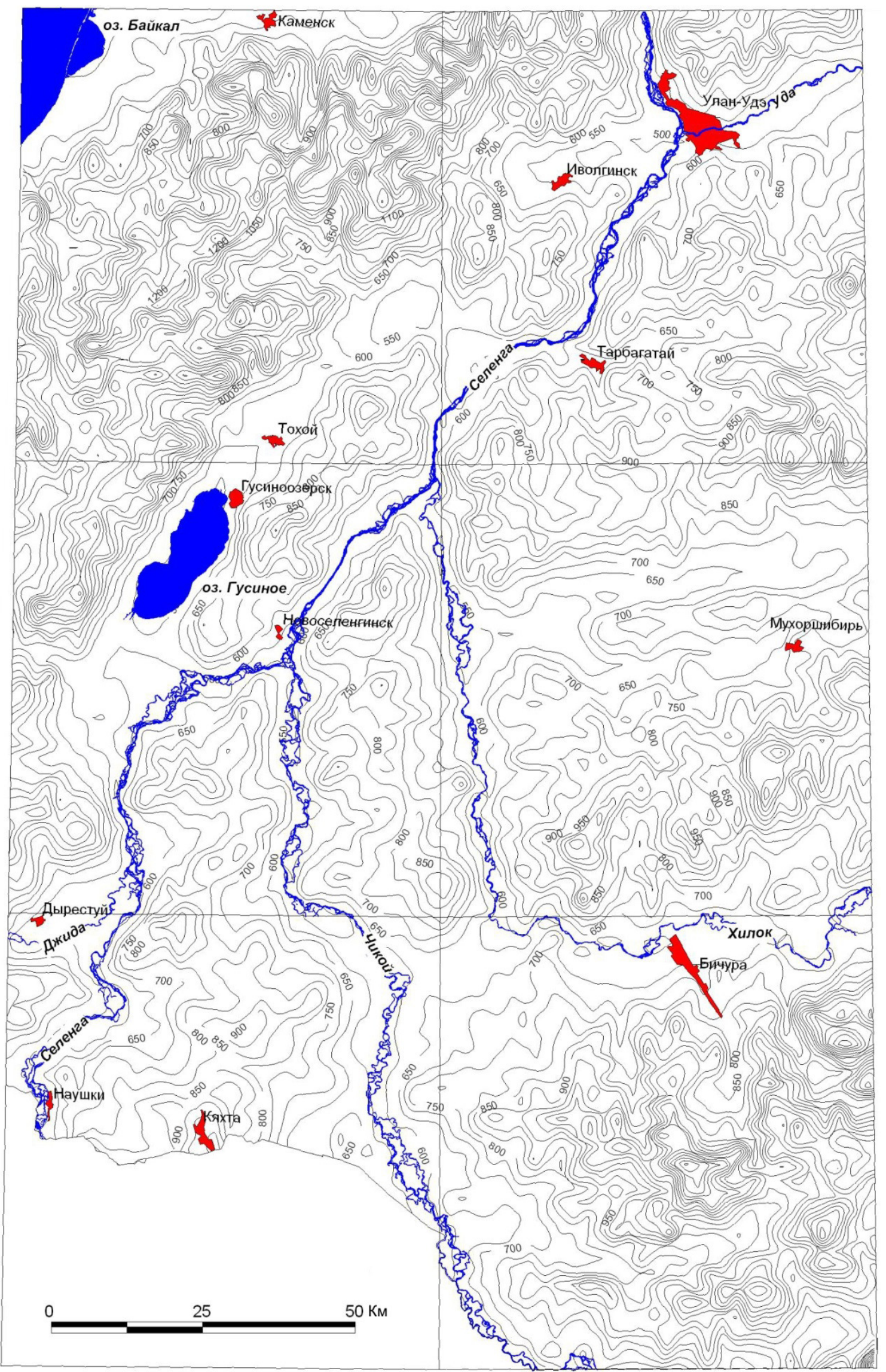

Puc. 4. Карта базисной поверхности юго-западного Забайкалья. 

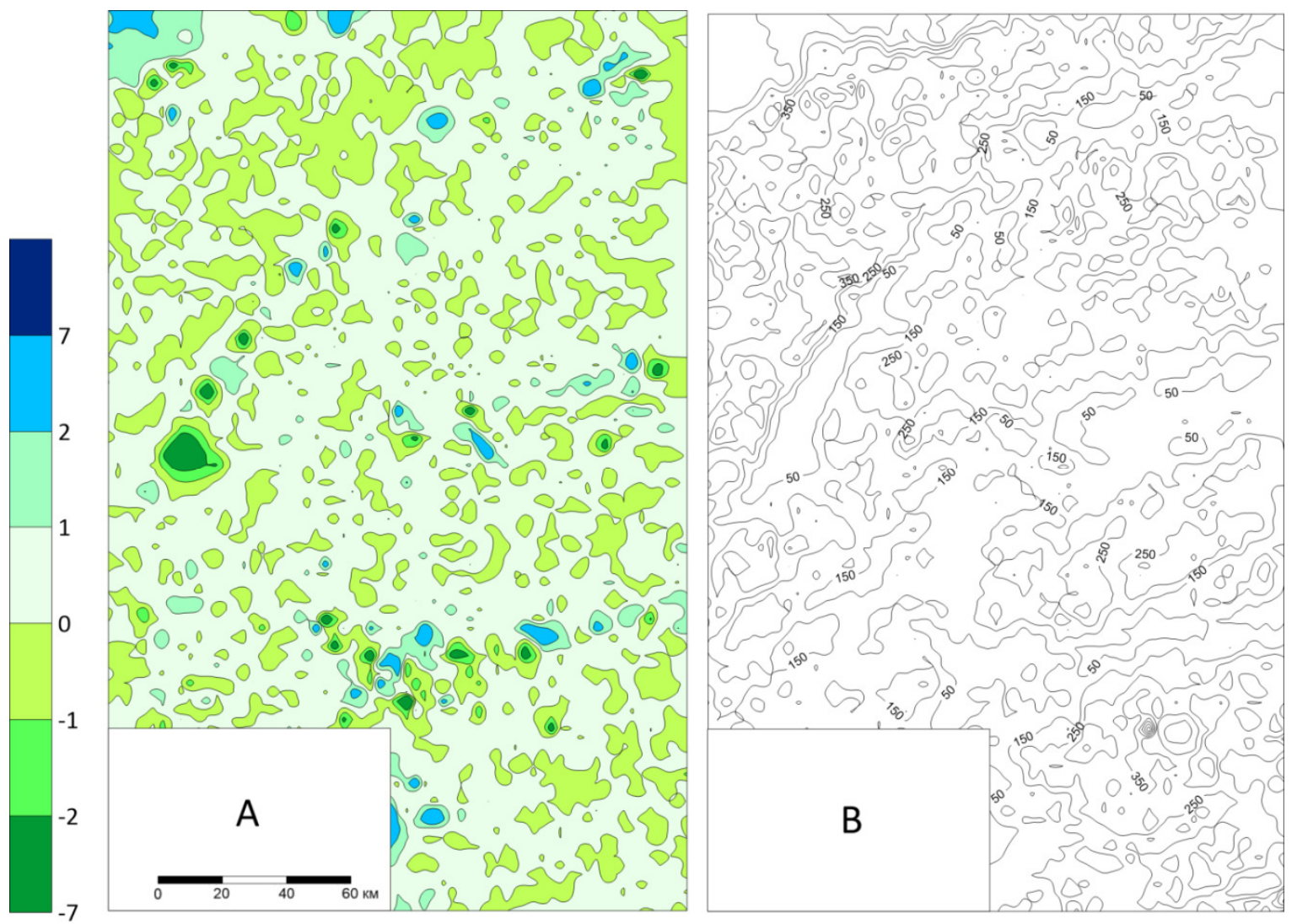

Puc. 5. Карты коэффициентов асимметрии распределения высот земной поверхности (А) и карта энергии рельефа (В).

В формировании Тугнуйской структуры большую роль сыграли бортовые рифтогенные разломы - листрические сбросы, сбросо-сдвиги. В результате движений по ним северный борт впадины приобрел облик ступенчатого грабена, а южный, осложненный выступом Тугнуйского хребта, ступенчатого рампа [10].

Неотектоническая структура Моностойского блока предопределена развитием мезозойской депрессии на смежной территории. Формирование этой структуры начинается в домезозойское время. В течение мезозоя и кайнозоя блок развивается унаследовано и испытывает положительные неотектонические движения [10].

В пределах Заганского блока, в его восточной части, встречаются реликты древней поверхности выравнивания, предположительно мел-палеогенового возраста. В настоящее время эти участи гипсометрически расположены в пределах высот 1200-1350 м [10]. Консеквентное залегание на склонах Заганского хребта аллювиальных отложений сибильдуйской толщи по данным геологического доизучения территории (В. С. Платов и др., 2002) говорит о сохранении неогенового рельефа до раннего эоплейстоцена. Области впадины приподнялись примерно на 100-150 м над смежными областями. Возможно, центральная часть блока испытывала несколько большее поднятие в неотектонический этап. В неоплейстоцене и голоцене наблюдается почти повсеместное накопление осадков аллювиального и делювиального генезиса в пределах русел рек и на склонах. Происходит врез речной сети, что говорит о понижении базиса эрозии. Такая обстановка сохраняется в пределах Заганского блока и до настоящего времени [8].

Хилок-Чикойская впадина представлена вулканотектонической депрессией, заложившейся вдоль системы Хилокского глубинного разлома [10], разделяющего Заганский и Малханский блоки. Как и большинство структур юго-западного Забайкалья, неотектоническая структура Хилок-Чикойской впадины унаследовала докайнозойский структурный план. В верхнем плиоцене здесь происходило формирование озерных и аллювиальных отложений тологойской свиты. В конце плиоцена и в начале эоплейстоцена территория испытывает некоторое погружение, что приводит к расширению областей аккумуляции. В четвертичном периоде происходит накопление аллювиально-озерных отложений сибильдуйской, хилокчикойской и кривоярской толщ, постепенное поднятие южного борта Хилок-Чикойской структуры. В конце неоплейстоцена скорость поднятия смежного Малханского блока значительно увеличивается.

По характеру неотектонической структуры Малханский блок близок к Хамар-Дабанскому. В пределах этого блока развиты реликты поверхности выравнивания, гипсометрически расположенные в пределах высот 1550-1650 м.

В миоцене территория представляла собой невысокое горное сооружение, ограничивающее с юга об- 
ласть активного осадконакопления. В плиоцене тектоническая активность территории возрастает. Это связано с образованием базальтовых лав снежинского комплекса. Реликты поверхности выравнивания расположены выше тел эффузивов не менее чем на 700 м, что позволяет принять эту величину за относительное положение Малханского блока в неогеновом рельефе. В неоплейстоцене поднятие территории продолжается, о чем свидетельствует глубокое врезание долин.

В неогене на территории Харгантуйского, Черногривенского и Черносопкинского блоков преобладал структурно-денудационный рельеф. Положительные структуры совпадали с выходом на дневную поверхность вулканоплутонических палеозойских структурно-вещественных комплексов. На смежной территории, в пределах Хилок-Чикойской впадины происходило накопление красноцветов тологойской свиты, как продуктов, коррелятных поверхностям выравнивания в пределах Малханского и Заганского блоков. На этой территории значительное осадконакопление отсутствовало, что может объясняться устойчивыми относительно слабыми тектоническими поднятиями [10].

Проведенные исследования позволяют сделать вывод о том, что использованная методика морфометрического анализа на основе стохастических моделей рельефа может быть включена в комплекс методов (геофизических и геологических) изучения неотектонических и современных тектонических движений при геологическом изучении территории Забайкалья. Это позволит существенно повысить информативность методов и экономическую эффективность геологических исследований.

ФГБОУ ВО Воронежский государственный университет Жаворонкин Олег Валерьевич, кандидат геолого-

минералогических наук, доцент кафедры общей геологии и геодинамики

E-mail: zhavoronkinov@mail.ru

Тел.: +7(473) 2208926

ФГБОУ ВО Воронежский государственный университет ФГБОУ ВО Российский государственный геологоразведочный университет имени Серго Орджоникидзе», Старооскольский филиал, г. Старый Оскол

Трегуб Александр Иванович, доктор геолого-минералогических наук, профессор кафедры общей геологии и геодинамики ВГУ

E-mail: tregubai@yandex.ru

Тел.: +7(473) 2208926

\section{ЛИТЕРАТУРА}

1. Зоненшайн, Л. П. Тектоника литосферных плит территории СССР / Л. П. Зоненшайн, М. И. Кузьмин, Л. Ш. Натапов. - М.: Недра, 1990, т. 1, 327 с., т. 2, 334 с.

2. Геодинамическая карта Палеоазиатского океана. Восточный сегмент / В. Г. Беличенко [и др.] // Геология и геофизика. - 1994. - № 7-8. - т.35. - С. 29-39.

3. Скляров, Е. В. Комплексы метаморфических ядер Кордильерского типа / Е. В. Скляров, А. М. Мазукабзов, А. И. Мельников. - Новосибирск: СО РАН НИЦ ОИГГМ, 1997, $182 \mathrm{c.}$

1. Жаворонкин, О. В. Применение статистических методов в морфометрическом анализе / О. В. Жаворонкин // Тезисы XIX Всероссийской молодежной конференции "Строение литосферы и геодинамика", Иркутск, 2001. - С. 100.

2. Порядин, В. С. Стохастические модели в морфоструктурном анализе / В. С. Порядин. - М.: Недра, 1985. - 152 с.

3. Философов, В.П. Основы морфометрического метода поиска тектонических структур / В. П. Философов. - Саратов, 1975. $-232 \mathrm{c}$.

4. Шарапов, И. П. Функции распределения высоты рельефа / И. П. Шарапов // Рельеф земли и математика.- М.: Мысль, 1965. - С. 72-79.

5. Базаров, Д. Б. Четвертичные отложения и основные этапы развития рельефа Селенгинского среднегорья / Д. Б. Базаров. - Улан-Удэ: БИЕН БФ СО АН СССР, 1968. - 167 с. 6. Ярмолюк, В. В. Магматизм и динамика формирования позднемезозойской - кайнозойской Южно-Хангайской горячей точки мантии (Монголия) / В. В. Ярмолюк, В. Г. Иванов. // Российский фонд фундаментальных исследований в Сибирском регионе (Земная кора и мантия). Тез. докладов ИЗК СО РАН, Иркутск, 1995, Т. 2. - С. 128-129.

7. Уфимцев, Г. Ф. Морфотектоника восточного побережья Байкала / Г. Ф. Уфимцев. // Геология и геофизика. -1999. №1. - C. 19-27.

Voronezh State University

Zhavoronkin O. V., Candidate of Geological and Mineralogical Sciences, associate professor of Department of General Geology and Geodynamics

E-mail: zhavoronkinov@mail.ru

Tel.: +7(473) 2208926

Voronezh State University

Moscow Geological Exploration Institute, Starooskolsky branch Tregub A.I., Doctor of Geological and Mineralogical Sciences, Professor of Department of General Geology and Geodynamics VSU

E-mail: tregubai@yandex.ru

Tel.: +7(473) 2208926 